$\xi=-1$

\title{
Second Language Acquisition and Mother Tongue Influence of English Language Learners - A Psycho Analytic Approach
}

\author{
A. Delbio ${ }^{1 *}$, R. Abilasha ${ }^{2}$, M. Ilankumaran ${ }^{3}$ \\ ${ }^{1}$ Research Scholar in English, Noorul Islam Centre for Higher Education, Kumaracoil, Kanyakumari District, Tamil Nadu, India. \\ ${ }^{2}$ Assistant Professor of English, Holy Cross College (Autonomous), Nagercoil, Kanyakumari District, Tamil Nadu, India. \\ E-mail:abilasharajan@yahoo.com \\ ${ }^{3}$ Professor of English, Noorul Islam Centre for Higher Education, Kumaracoil, Kanyakumari District, Tamil Nadu, India. \\ E-mail:mikumaran@yahoo.com \\ *Corresponding author E-mail:delbiodel@gmail.com
}

\begin{abstract}
Language is a tool used to convey one's thoughts, feelings and needs. Mother tongue is the language acquired by everyone ever since his birth. A learner encounters mother tongue influence while learning or speaking a foreign language or target language. Mother tongue influence is something that affects a person's thought process in a sense that he thinks in mother tongue and expresses in English or a second language. People use incorrect pronunciation of words while communicating in English language as they are influenced by the sound patterns of their mother tongue. A second language learner has an unconscious preference to convey his customs from his first language to the target language. The influence of mother tongue has become a significant region and is generally referred to as 'Language Interference'. Every language learner comes across this issue. Students, sometimes, use words from their parent language while communicating in English. This paper speaks about the difficulties faced by the learners of the second language and the causes of first language influence. This paper attempts to bring out the ways to avoid the overwhelmed influence of mother tongue and gives some notions to the students to develop their second language skills.
\end{abstract}

Keywords: Language, mother tongue, learning, influences, acquisition, pronunciation, communication, non-native speaker.

\section{Introduction}

Mother tongue is the language that a child imbibes from his mother. Language is used to achieve the creative ideas and to obtain the complicated methods pertaining to communication. The scientific study of language is called linguistics. Language is used to express one's ideas and share with others. People are capable to exchange knowledge, beliefs, opinions, commands, thanks, feelings by using language. One can express amusement, pleasure, approval, or bitter feelings with the help of language. Many languages are around the world. English language is one tool to start our view point. People can check the theories of foreigners against their experience. Moreover, they can also spread their theories among the international audience and readers.

The modern language teaching is created for communicative method. It highlights the teaching of English language by using the same language, which is English language. The concept of discarding the parent language is a difficult job for most of the learners. In that situation, the learner finds difficulty in learning a foreign language without the influence of the mother tongue. Most of the instructors use translation as a professional skill, whereas others may use mother tongue to teach the target language. Nonnative teachers find easy to teach the target language with the help of parent language but the native teacher of second language may neglect to use the mother tongue. They find, it is not the correct way of teaching the target language. The psychological way of language acquisition teaches the natural method to acquire the language.

\section{Psychological approaches in second language acquisition}

Second language acquisition is a psychological process. Naturally the learner achieves in acquiring the first language. The learner may fail in attaining a new language, because the students are not interested in learning a new language. The instructor can teach the importance of the second language and instill interest in the learners.

Natural process is the best method in language acquisition. In learning a new language, the learner needs to spend extra force to overcome the learning disability. They may involve in psychological process of acquisition, because acquisition is given more priority than learning a language. The factors which involved in acquisition are communication, recapitulation, stability in learning, trial and error, interference of the acquired language, translation method.

\subsection{Communication}

Communication is one of the major techniques involved in acquiring the new language. Through this, the teacher can motivate and convey prominence of the second language to the learner.

They can practice in target language. Bilingual method can also be followed in communication. It can be used for translating the new vocabulary, so that the learner finds easy to acquire the target language. Regular practice may lead a great success. 


\subsection{Recapitulation}

Learning a new word may store only in short term memory. Revising the same word for several times would get stored in long term memory. The teacher can revise the grammar rules, structure of the sentence, pronunciation, etc. for getting memorized. This brings interest among the learner and they acquire the target language without conscious effort. Lack of practice plays a main role in failure of language learning. The learner should practice all the four skills such as listening, speaking, reading, and writing (LSRW). Audio tools are needed to improve the skills. Most of the teachers are unable to teach the English language effectively because they face a lot of problems due to the lack of teaching aids.

\subsection{Stability in learning}

The learner can maintain continuity in learning a target language. The learners can develop the reading ability to develop the target language. In that situation, stability is very much needed. Fluency can be improved through continuous practice in target language. The teacher can be more conscious about the steadiness of the learners. The learner can easily forget the things which they learn. Stability units the process and resumes the success.

\subsection{Trial and Error}

Trial and error is one of the best practices to learn a new language. The students may commit mistakes in pronunciation and in grammar rules. The mistakes can be corrected by the teacher and the students can overcome the mistakes. The students can work hard to correct their errors. The error may not get revised in the sentence. They can apply the grammar rules in the sentences and the instructor may correct the mistakes committed.

\subsection{Translation Method}

Translation method is used in Indian classrooms. In translation, it helps the learners to understand the content and abstract idea. They fail in learning the language. Thus, translation method is a problem in learning English.

Most of the problems arise in the interference of mother tongue. The teachers and the students are very much fluent in speaking their mother tongue. When they speak in mother tongue, they use English word in between. They forget the real use of English language. They fail to concentrate on stress, intonation and pronunciation of the language.

\section{Mother tongue influence}

An individual learns the parent language from his birth. It is difficult to get rid of the influence of the mother tongue. Students also feel inferior because of mother tongue influence. Non-native speakers are not capable to communicate efficiently and effectively.

Second language learners have a tendency to transfer everything from his mother tongue to the second language. The learners translate the target language into their mother tongue and speak only in parent language.

Those learners find difficulty to speak in target language, because of lack of practice in second language.

The students may interact only in their regional language in school hours. This may trouble in learning a target language. From the birth itself the child starts to acquire the things by listening to the parents in the language spoken by them. Biswajit says "The impact and focus of regional language overshadows the learning of English".

The students learn the English language at their school level, but they cannot produce any sentence without error.

\subsection{Bilingual method}

In Bilingual method two languages are used. The language to be learnt and the mother tongue are used. A student learns the mother tongue and learns the foreign language words at the same time. Bilingual method is completely different from translation method. To explain the meaning of difficult words only the teacher uses mother tongue. Students get a lot of practice in sentence patterns. That is not given in the translation method. A child learns the mother tongue in a real situation. He connects the meaning of words with his own experience. In this way, the child forms the idea in different concepts in mind. These situations might have been created while teaching a foreign language. Bilingual method makes use of linguistic habits formed during learning the mother tongue.

\subsection{Principles of bilingual method}

- Bilingual Method allows the use of first language. In Bilingual method, mother tongue is used to express the meaning of words, sentences and idioms to the learners.

- Bilingual Method does not have to create any fake situations. The teacher is not desired to create situations to making the meaning of English sentences and words clear to the students. This method saves the teachers from making unnatural situations.

- This method is an improvement over other methods. Bilingual method is an advanced method upon both translation and direct method.

- In this method, there is more time for practice. In this method, there is no need for artificial situations, so the teachers can use that time for pattern practice and teaching sentences and words.

- In Bilingual method, the teacher can use the mother tongue. The students only practice formats of English.

\subsection{Merits of bilingual method}

- Bilingual method saves time from making unnatural situations.

- The students get the clear idea about the sentences because it has already been explained in their mother tongue.

- The students get a lot of practice in speaking English language.

- Anyone can teach this method.

\subsection{Demerits of Bilingual Method}

- The difference between the characteristics of two languages will confuse the students.

- $\quad$ Too much of mother tongue may not be good. This will become a failure.

- This method diverts the students by over use of mother tongue.

- The students may be obsessed by mother tongue and it will become a bad habit among the students.

- Student's pronunciation may become poor by the influence of mother tongue.

- Bilingual method is not useful for the senior level students.

- Using of mother tongue when speaking English language spoils the fluency.

\subsection{Problems Faced by the Students}

There are many psychological problems in learning the target language. Some problems are discussed. The learner may find 
difficulty in learning English language. Most of the students learn English by compulsion to get pass in schooling and becomes graduates. They aim only at the pass mark. They do not learn English as a tool of communication. They learn it only for exam purpose. This disinterest makes them fail in learning the language. They fail to develop the language skills in target language. Those students lack confidence while communicating in English. When the child is neglected to speak in a public place or in a class, the special care should be given to the children. Otherwise the child faces problems in future. These students should be given opportunity in classroom to overcome the fear to speak in public places.

The main problem in learning method is that the students and the teacher consider English as a subject rather than language. The teacher concentrates only on prose, poetry, essay, etc. When poetry is taught, the teachers need to be expressive. For example, if the poem expresses sorrow, the student should cry. This type of experience is hardly found in classroom teaching. The teacher is in hurry to complete the portion. They think that it is waste of time to arouse emotions and interactions with the students. Students from rural and urban areas face a lot of problems in language learning. The parents of the students are uneducated and so they are facing the problem in learning language. One who hails from well-educated family will face fewer problems than those of urban area. The Educated family child is given enough care to improve the target language. On this contrary, the rural area child is given little care to learn the target language.

Economic status is one of the psychological problems faced by the learner. Poor pupils do not have enough money to go for the best school which provides quality education. The pupils from rich family have quality education and they are rich in language by comparing to poor pupils. This leads to the learners from poor family to have inferiority complex among them. Lack of awareness brings the psychological problem among the learners.

The sound system of the new language brings problematic in learning. Imitation plays a main role language learning as they are acquired the parent language. In olden days grammar translation method is used to teach the second language. Through this method, the students are well versed in grammar rules but they cannot speak fluently in target language. In this method, the teacher use to translate each and every word in mother tongue, so the student lacks fluency in second language. Thus, the use of first language in the classroom can be limited. The conflicting area in language acquisition is pronunciation. It is also the major factor in second language acquisition. The students are using the wrong pronunciation. In this case, they can listen to the native speaker to improve the target language. While teaching, the articulation of the individual sound is not given priority. In Indian classrooms, the teacher may not give stress to the accent of the language. There is large number of dialects found in language. It is hard to practice the complete speech pattern in the classrooms. It is a challenging task in Indian classrooms. The pronunciation is given importance like grammar and vocabulary in communication, it cannot be refused. This all happens only because of the influence of mother tongue. The influence of the parent language brings the incorrect pronunciation.

Some difficulties faced by a second language learner are in the area of segmental phonology of English. There are major differences in the use of stress and intonation between English and Indian languages. Another problem faced by the language learners are thinking in mother tongue. Many learners have this problem. Thinking in mother tongue also causes mother tongue influence. The learner needs to think in target language, so that most of the problems can be rectified. Problems arise only when the second language contains words which are not used much in the mother tongue. Non-native speakers use case-endings to express the meanings which are communicated by prepositions in most European languages. Non-native English language learners finds difficult in the use of preposition. Non-native speaker gets not only trouble in learning a language, but in noticing it. Mother tongue has a role while teaching or learning a language. Mother Tongue can also involve in developing the second language. It has both positive and negative effects on second language learning.

Talking in mother tongue relates to learner's identity. The influence of the mother tongue brings to common facts. They are negative transfer and positive transfer. Positive transfer may relocate the skills of parent language into target language. In the negative transfer, it may relocate the linguistic differences. The regional language dominates the learner of English language. They prefer mother tongue at home and with the surroundings. They neglect to use English language for interaction. The activities which involved in home may not give room for English. In classroom, the students may depend on mother tongue. It brings disadvantage in classrooms. They fail to realize the importance of English language. They need to practice in target language to attain a language. The pattern of mother tongue and second language has little difference. The structure of the sentence, articles, prepositions cannot be compared with those of other languages all the times. They cannot try to impress their mother tongue with target language. This brings barriers in language learning.

\subsection{Suggestions}

Most of the learners come from different culture and language backgrounds. The teacher can provide opportunities to expose themselves in target language by sharing their ways of thinking, which may reduce mother tongue influence. Students may learn faster in play way methods than the narrative method. Teaching of English to learners is a challenging task, so it needs to be controlled properly by professional teachers of English. The learner needs to be taught with visual and audio lingual method to get success. The children can be provided with opportunities and new experiences.

Teachers can make the students listen and speak in the second language as much as possible. The students can also join social groups with native speakers of their target language. This practice will make them reduce the mother tongue influence. Language learning is different from learning other subject because it is a medium of expression. Real language learning takes place outside books or classroom. If one really wants to acquire English language, he must make it routine to use of the target language. One must give opportunity to the language they want to speak or learn. Reading the newspaper or magazine will be useful. Students even find a script for themselves favorite TV show and act like it. This is a best method to practice pronunciation, because the students need to concentrate on making English sounds. They need not worry about structure of the sentence and grammar rules. Learning a new word every day and practicing it in different sentences brings a great success.

The teachers should teach the students to speak in English as much as possible. Thinking does not affect directly. Continued use of English language for a long period in many situations will help the process of thinking in English. Teachers can employ the same way as they acquired their mother tongue and give motivation and care instill confidence among the learners for better performance. Another way is expelling mother tongue from classroom. This will affect some learners especially those who studied in vernacular medium schools. The teachers can make the learners alert that the reason for not using mother tongue is to improve their second language skill. The language classroom can provide enough opportunity to avoid the mother tongue influences.

\section{Conclusion}

English is a growing language. No one can ever say that he is a master over English language. All are all learners. The only difference is that they are placed at different levels of learning. Students have to practice a lot to overcome their mother tongue 
influence. English language learners usually depend on their mother tongue while learning English and that must be avoided. The students can independently create reading comprehension exercises, back-translation and summary writing activities that help them to raise awareness of the differences between English and mother tongue and process linguistic development. Teaching English as a second language is not an easy job. Some new techniques can be followed in order to develop the second language. It can be taught with fun, if the teachers choose an innovative method to develop the target language. Before starting the process of teaching the target language, it is better to learn the psychological background of the learners. Motivation plays a major role in learning a language. To get an achievement and success motivation is the base. By giving some rewards, the quality teaching of teachers can be improved. The psychological analysis may help the teacher to get success.

\section{References}

[1] Abilasha R \& Ilankumaran M, "The Need of Professional Communication in English for Engineering Students", $A n$ International Refereed e-Journal of Literary Explorations, Vol.3, (2015), pp.143-159.

[2] Abilasha R \& Ilankumaran M, "The Impact of ICT Enabled English Language Teaching on the Engineering students of Rural and Semi-Urban Areas of South Tamilnadu", Journal of Chemical and Pharmaceutical Sciences, Vol.9, No.1,(2016), pp.434-439.

[3] Abilasha R \& Ilankumaran M, "New Trends in English Language Teaching. A Novel perspective", International Journal on Studies in English Language and Literature (IJSELL), Vol.2, No.11, (2014), pp.46-52.

[4] Bhushan R, The Neglected Resource for English Language Teaching and Learning, Language in India Web, (2010).

[5] Broadbent DE, "Psychological Aspects of Short-Term and LongTerm Memory", Proceedings of the Royal Society of London, Series B, Biological Sciences, Vol.175, No.1041, (2014), pp.333-350.

[6] Brown DV, "Cognitive Pruning and Second Language Acquisition", The Modern Language Journal, Vol.56, No.4 (1972), pp.218-222

[7] Hakes DT, "Psychological Aspects of Bilingualism", The Modern Language Journal, Vol.49, No.4, (1965), pp.220-227.

[8] Abilasha R, "Short Stories as a Genre of Literature to Teach Speaking Skills", International Journal on Studies in English Language and Literature (IJSELL) with IF 3.537, Vol.6, No.1, (2018), pp.25-27.

[9] Abilasha R, "Smart Classrooms: An In-built Innovation of the Millennium English Language Education", International Journal of English Language and Literature in Humanities (IJELLH) with IF 5.7, Vol.6 No.4, (2018), pp.348-355.

[10] Delbio A, "Psychological Influence of Dyslexia and Apraxia Affecting Second Language Acquisition on Young Learners", International Journal of English Language and Literature in Humanities (IJELLH) with IF 5.7, Vol.6, No.4 (2018), pp.81-90.

[11] Jeya Gowri K, "Challenges involved in ELT During Transition from Higher Secondary to Tertiary Level", International Journal of English Language and Literature in Humanities (IJELLH) with IF 5.7, Vol.6 No.4, (2018), pp.31-38.

[12] Micah V, "Configuring Theories and Techniques to Minimize Mother Tongue Influence (MTI) in Second Language Classrooms", International Journal of English Language and Literature in Humanities (IJELLH) with IF 5.7, Vol.6, No.4, (2018), pp.17-29.

[13] Jerose Flashan U, "The Objectives of Teaching English as a Second Language at Different Levels of Learning", International Journal of English Language and Literature in Humanities (IJELLH) with IF 5.7, Vol.6, No.4, (2018), pp.39-52.

[14] Vinothees AP, "Importance of Accuracy in Developing English Speaking Skills", International Journal of English Language and Literature in Humanities (IJELLH) with IF 5.7, Vol.6, No.4, (2018), pp.143-151.

[15] Deepa P, "Activity Based Learning Enhances Speaking Skills with Poetry as a Tool", International Journal of English Language and Literature in Humanities (IJELLH) with IF 5.7, Vol.6 No.4, (2018).
[16] Abinisha S, "The Harvest of Humans as Portraryed by Manjula Padmanabhan in Harvest", International Journal of English Language and Literature in Humanities (IJELLH) with IF 5.7 Vol.6 No.4, (2018), pp.338-341.

[17] Sreena S \& Ilankumaran M, "Types of Communication Skills and the Ways and Means to Enhance Them", International Journal of English Language and Literature in Humanities (IJELLH), Vol.6, No.4, (2018), pp.492-498.

[18] Abdul Majeed CT, "Teaching English Using Programmed Instruction", International Journal of English Language and Literature in Humanities (IJELLH) with IF 5.7, Vol.6, No.4, (2018), pp.511-521.

[19] Abilasha R, "Fourth World Literature: A mouth Piece of Indigenous Languages", World Literature: A Critical Outlook, (2018), pp.1-6.

[20] Delbio A, "English Language: A Tool to Express the Repressed Psyche of the Fourth World", World Literature: A Critical Outlook, (2018), pp.42-45.

[21] Jeya Gowri K, "Prescriptions of Fourth World Elements at the Tertiary Level for Global Acclaim", World Literature: A Critical Outlook, (2018), pp.97-100.

[22] Sreena S, "The Role of Teachers in Developing Second Language Acquisition", International Journal of Research in Humanities, Arts and Science with IF 2.135, Vol.2, No.9, (2018), pp.40-43.

[23] Abilasha R, "English Language Teaching: Challenges and Strategies from the Indian Perspective", International Journal of Engineering and Technology (IJET), Vol.7, No.3, (2018), pp.202-205.

[24] Delbio A, "Theories, Techniques, Methods and Approaches of Second Language Acquisition: A Psychological Perspective", International Journal of Engineering and Technology (IJET), Vol.7 No.3, (2018), pp.192-197.

[25] Jeya Gowri K, "Application of Theories, Techniques, Methods and Approaches to Develop Second Language Skills - A Study based on Transition from Schooling to College", International Journal of Engineering and Technology (IJET), Vol.7, No.3, (2018), pp.210215.

[26] Deepa P, "Teaching Literature Enhances Communication Skills A Study with Special Emphasis on Poetry", International Journal of Engineering and Technology (IJET), Vol.7, No.3, (2018), pp.187-191.

[27] Harmer J, The Practice of English Language Teaching. England: Pearson Education Limited, (2001).

[28] Kavaliauskiene G, Role of Mother Tongue in Learning English for Specific Purposes, ESP World, Web, (2009).

[29] Sharma S, Mother Tongue Influence on English Language Learning Scholarly Research Journal for Humanity Science and English Language, (2015), pp.2165-2169.

[30] Sundaram M, Teaching of English Optional I \&II, Kavyalaya, Chinnalapatti, (2011)

[31] Tripathy B, "Teaching English to young Learners: Multilingual Concept in India, a Review", The Journal of English Literature, (2014), pp. 101-103. 